\title{
Surgical challenges of down syndrome with developmental dislocation or dysplasia of the hip undergo operative treatment under anaesthesia in teaching hospital
}

\author{
Mika K. Prasetyo*, Sulis Bayusentono
}

\begin{abstract}
Department of Orthopaedic dan Traumatology, Medical Faculty of Airlangga University, Dr. Soetomo General Hospital Surabaya, East Java, Indonesia
\end{abstract}

Received: 21 April 2020

Revised: 31 May 2020

Accepted: 02 June 2020

\author{
*Correspondence: \\ Dr. Mika K. Prasetyo, \\ E-mail: new.micu@gmail.com
}

Copyright: () the author(s), publisher and licensee Medip Academy. This is an open-access article distributed under the terms of the Creative Commons Attribution Non-Commercial License, which permits unrestricted non-commercial use, distribution, and reproduction in any medium, provided the original work is properly cited.

\begin{abstract}
Developmental/dislocation of the hip is one of the orthopaedic issues and the most common problem of the hip in down syndrome (DS). Down syndrome often arises with its general laxity problematics, one of the things is developmental dislocation/dysplasia of the hip (DDH). In chronic cases, surgery is a must, and this is mentions in several journals. Some complications can occur in the process of anaesthesia with intubation. We report two cases, both of which are seven years old with patients in the first case experiencing DDH and patients in the second case experiencing dislocation. The first patient had open reduction surgery with capsulotomy and internal fixation. The second patient, close reduction, and hemi spica installation. The first patient has trouble breathing one week after surgery, and then the tracheotomy is performed. A tracheotomy performed for almost two months and hemi spica removed in September 2019. After hemi spica removal, the patients were then routinely controlled for rehabilitation polyclinics, and the results improved.
\end{abstract}

Keywords: Developmental dislocation hip, Down syndrome, Laryngomalacia

\section{INTRODUCTION}

Down Syndrome often arises with its general laxity problematics, one of the things that are experienced by down syndrome patients who come to hospital is developmental dislocation/dysplasia of the hip (DDH). In chronic cases, surgery is a must, and this is often mentioned in several journals. Types of respiratory tract disorders in the larynx and trachea in children that are often found are abnormalities such as trachea bronchomalacia, subglottic stenosis (congenital or acquired), and tracheal stenosis. Children with down syndrome have a characteristic level of particular subglottic stenosis and are sometimes found asymptomatic. Children with down syndrome also have smaller trachea, so an anesthesiologist always uses a smaller endotracheal. if there is a failure in the installation, it can cause respiratory tract stenosis and worsen the symptoms. ${ }^{1,2}$

\section{CASE REPORT}

We reported two cases, both of which are seven years old with patients in the first case experiencing DDH and patients in the second case experiencing dislocation. Both cases treated operatively; the first case was done by senior orthopedics in the central operating room for two hours electively using the method of open reduction in capsulotomy and internal fixation. The second case was done by an orthopedic resident in the operating room of 
the emergency department on CITO for three and a half hours with the method of closed reduction and hemi spica installation.

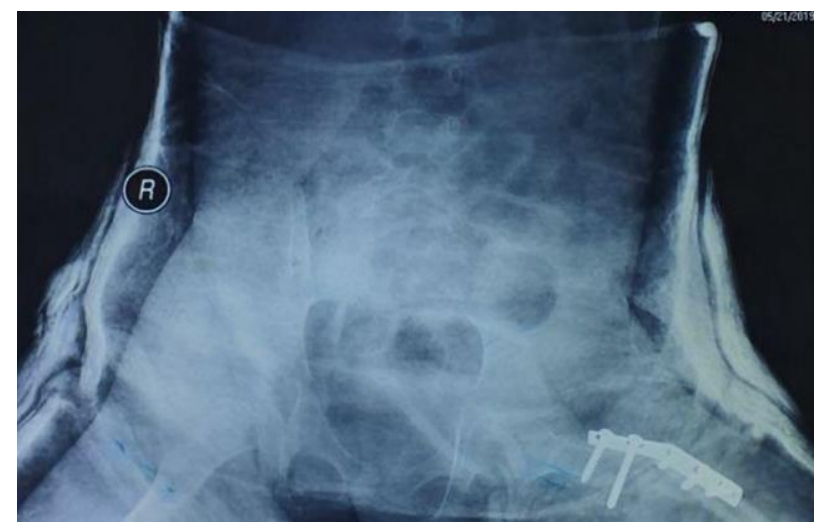

Figure 1: Post-operative pelvic X-ray of the first patient.

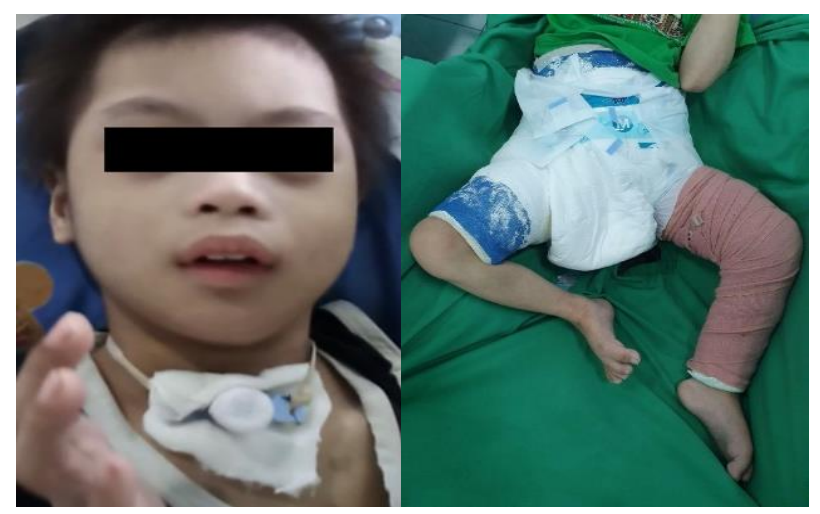

Figure 2: Post tracheotomy and clinical photo of the hip of the first patient.

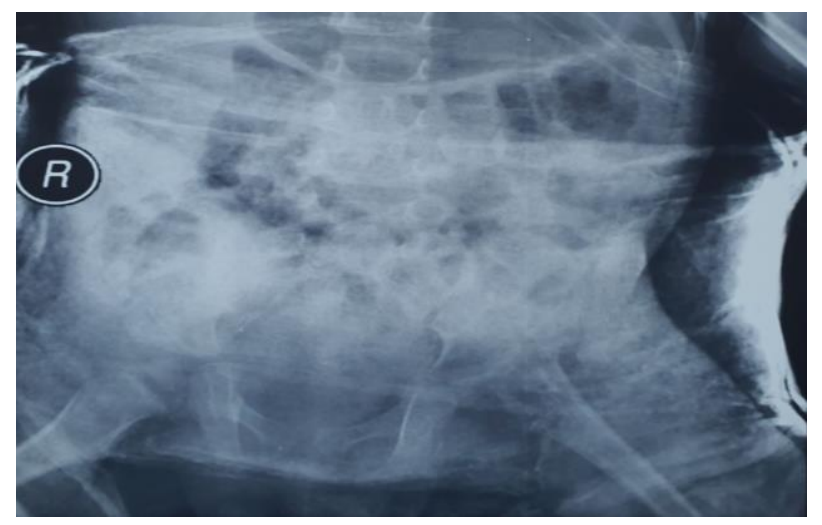

Figure 3: Post-operative pelvic X-ray of the second patient.

The first patient has trouble breathing one week after surgery, then the tracheotomy is performed; meanwhile, the second patient recovered a few days later and found no problems. One week later, the second case-patient could go home. In the first patient, a tracheotomy performed for almost two months, and hemi spica removed in September
2019. After hemi spica removal, the patients were then routinely controlled for rehabilitation polyclinics, and the results improved.

\section{DISCUSSION}

Down syndrome patients with general laxity occur in all parts of the body, especially in the respiratory tract of the epiglottic region and aryepiglottic folds, which form like an omega symbol. Obstacles to surgery also increase the risk during and after anaesthesia. Intubation also has difficulty due to airway obstruction and subglottic stenosis. Excessive manipulation of this section will raise the potential for challenges in intubating anaesthetics. As a result of excessive manipulation will cause laryngomalacia, which leads to upper respiratory blockage. Laryngomalacia (LMA) is a congenital abnormality in the laryngeal cartilage. Dynamic lesions cause a collapse of the supraglottic structure at the time of inspiration, causing airway obstruction. Besides this, morphological changes in the epiglottic shape, degree of the aryepiglottic fold, flaccidity, and hypotonia in muscles can increase the prevalence of laryngomalacia, which leads to upper respiratory obstruction and stridor. Those will lead the anesthesiologist to make the airway through a tracheotomy. 3,4

Preparation for upper airway obstruction with an oral airway will decrease the chances of hypoxia on induction. In patients with subglottic stenosis, an LMA, or smaller endotracheal tubes should be available during intubation to lessen the risk of airway trauma. Patients should be monitored closely postoperatively until they have fully recovered from anaesthesia. Airway maneuvers like jaw thrust and chin lift may be required to counteract the obstruction that can occur due to hypotonia. 5,6

Advanced medical management and expectations for children with DS have increased in the past 10 to 20 years. Lifestyle and life span have increased significantly. Much of this progress is due to aggressive surgical interventions. Along with the increase in surgical procedures performed on children with DS, the emergence of an awareness of the increase in postoperative airway difficulties has also been realized by anesthesiologists. In all children, both with and without DS, confirmation of endotracheal tube compatibility using leak testing must be a routine part of the intubation process. Not only is the data in the tabular format published in the anesthesia textbook used as a guide, but also the variability in all children must also be taken into account. Some research confirms that children with DS have smaller tracheal airways than normal children. Besides, for children with DS, there is a significant difference from the standard size of endotracheal tubes recommended for children in anesthesia textbooks. The endotracheal tubes for children with DS must be two sizes smaller at initial intubation compared with non-DS children. In addition, the compatibility of the cylinder must always be confirmed by 
leakage testing. Safe intubation practices like this will help reduce post-intubation complications in DS. ${ }^{7,8}$

\section{CONCLUSION}

Patients with DDH need to be aware of during the anesthesia process. One of the factors that influence this condition are resident of anesthesiologists who carry out intubation procedure must be supervised by supervisors in performing anesthesia in teaching hospitals and the compatibility of the cylinder must always be confirmed by leakage testing, another factor is operations that are 'quick in-quick out' in operative treatment.

Multidisciplinary medical management is required in order to maintain a better quality of life for DS. The varieties of specialties involved in the care of patients and the early diagnosis and appropriate treatment; severe disability can oftentimes be prevented.

Funding: No funding sources Conflict of interest: None declared

Ethical approval: Not required

\section{REFERENCES}

1. Mik G, Gholve PA, Scher DM, Roger F, Green DW. Down syndrome: orthopedic issues. Current Opinion Pediatrics. 2008;20:30-6.

2. Hamilton J, Yaneza MMC, Clement WA, Kubba H. The prevalence of airway problems in children with
Down's syndrome. Int J Pediatric Otorhinolaryng. 2016;81:1-4.

3. Landry AM, Thompson DM. Laryngomalacia: Disease Presentation, Spectrum and Management. Int J Pediatrics. 2012: 1-6.

4. Shott SR. Down Syndrome: Analysis of Airway Size and a Guide for Appropriate Intubation. Laryngoscope. 2000;110:585-92.

5. Akpek EA, Kayhan Z. Difficult Intubation in Pediatric Cardiac Anesthesia. J Cardiothoracic Vascular Anesthesia. 2004;18(5):610-2.

6. Ayari S, Aubertin G, Girschig H, Abbeele VDT, Mondain M. Pathophysiology and diagnostic approach to laryngomalacia in infants. European Annals Otorhinolaryng Head Neck Diseases. 2012;129(5):257-63.

7. Jacobsen FS, Hansson G. Orthopaedic disorders in Down's syndrome world health organization about the term Mongol. Current Orthopaedics. 2000;14:215-22.

8. Mitchell RB, Call E, Kelly J. Diagnosis and Therapy for Airway Obstruction in Children with Down Syndrome. Arch Otolaryngol Head Neck Surg. 2003;129:642-5.

Cite this article as: Prasetyo MK, Bayusentono S. Surgical challenges of down syndrome with developmental dislocation or dysplasia of the hip undergo operative treatment under anaesthesia in teaching hospital. Int J Res Orthop 2020;6:848-50. 